\title{
Interlanguage Syntax of the Noun Phrase in English: An Error Analysis of Third Year High School Students of English in Zawiya, Libya
}

\author{
Mohamed Ataieb Ahmad Hmouma \\ (English Department, Abu-Issa Faculty of Education, Zawiya University, Libya)
}

\begin{abstract}
This research examined the interlanguage syntax of high school students of English in Zawiya, Libya in the area of the noun phrase (NP), focusing on the closed system elements that can occur before or after the noun head. It is based on the assumption that those students encounter difficulties in forming and using the English noun phrase. The findings demonstrated that a great deal of students' errors could be explained by overgeneralization and interference from students' mother tongue, though some other errors challenge explanations offered by contrastive analysis of English and Arabic.
\end{abstract}

Keywords - Determiners, Error Analysis, Interlanguage, Nouns, Noun Phrase, Syntax

\section{Introduction}

The Noun Phrase (NP) and the Verb Phrase (VP) are equally important. VP has been the dominant focus of attention in course books, syllabuses, and teacher training programmes. Teachers often over-emphasize verbs and forget about the central importance of nouns and NPs. Verbs are certainly important, but not much can be said without nouns. So NPs should not be ignored by syllabus and material writers as well as teachers. Consequently, this case study looked at what types of NP errors are most frequent by students, what possible sources of errors are, and suggested recommendations in order for students to get rid of those errors.

\subsection{Literature Review}

Before the 1960s language was not considered to be a mental phenomenon. Like other forms of human behaviour language was learnt by processes of habit formation. A child learns his mother tongue by imitating the sounds and patterns he hears around him. Under the influence of cognitive linguists, this explanation of L1 acquisition was criticized. Language cannot be verbal behaviour only, since children are able to produce an infinite number of utterances that have never been heard before [1]. This creativity is only possible because a child develops a system of rules. A large number of studies have shown that children actually do construct their own rule system, which develops gradually until it corresponds to the system of the adults. There is also evidence that they pass through similar stages acquiring grammatical rules. Through the influence of cognitive linguists and L1 acquisition research the notion developed that L2 learners, too, could be viewed as actively constructing rules from the data to which they are exposed and that they gradually adapt these rules in the direction of the L2. However wrong and inappropriate learners' sentences may be in regard to the TL system, they are grammatical in their own terms, since they are a product of the learner's own language system. This system gradually develops towards the rule-system of the L2. The various shapes of the learner's language competence are called Interlanguage (IL). One of the principal contributions to IL is its underlying claim that the learner's knowledge is to be seen as a unified whole, in which new knowledge is integrated and systematically reorganized with previous knowledge of the learner [2]. The term "IL" draws attention to the fact that the learners' language system is neither that of his mother tongue nor that of the L2, but contains elements of both. Therefore, errors should not be seen as signs of failure only, but as evidence of the learner's developing system [3].

An IL is a term used to describe an emerging linguistic system that has been developed by a learner of a foreign language who has not become fully proficient yet but is only approximating TL: preserving some features of his/her L1, in speaking or writing the L2 and creating innovations. An IL is idiosyncratically based on the learners' experiences with the L2. It can fossilize at any of its developmental stages. The IL consists of: L1 transfer, transfer of training, strategies of L2 learning (e.g. simplification), strategies of L2 communication (e.g. do not think about grammar while talking), and overgeneralization of the L2 patterns. IL is based on the theory that there is a "psychological structure latent in the brain" which is activated when one attempts to learn a foreign language [4].

An NP is a phrase which has a noun as its head. The NP is one of the most crucial elements of a text. Almost all sentences contain NPs whether as a subject, an object, a complement or a modifier. Thus, the 
occurrence of the NPs plays an important role in building up the text. Moreover, the effective usage of NPs helps students to make a good piece of writing [5].

The articles are the most frequent morphemes in English, and despite their frequency they are acquired by native speakers at a late stage. Though they are grammatically complex since they involve one transformation [6], they are semantically complex and their semantic complexity is what makes them difficult to learn.

Definiteness versus indefiniteness is a universal feature in linguistics. However Arabic and English express these concepts differently. In Arabic, a definite noun is usually marked by the definite particle, while the indefinite noun is unmarked. In other words, Arabic has no article equivalent to $\boldsymbol{a}$ or $\boldsymbol{a n}$ [7].

Reference [8] pointed out that error analyses conducted on learners of English from various language backgrounds have consistently shown that articles in English are difficult to learn. The pattern of error across language backgrounds is strikingly similar. Most of these studies attribute the source of error to mother tongue interference.

Reference [9] argued that many English as a Foreign Language textbooks do not do justice to measure words or collective nouns and say little about quantifiers beyond contrasting the use of much/many and the meaning of $\boldsymbol{a} \mathbf{f e w / f e w}$ and $\boldsymbol{a}$ little/little. They rightfully conclude that the quantifier-collector system in English is far more complicated than these textbooks would suggest and that it needs to be stressed more than it is at the present.

Regarding errors committed in the use of nouns reference [7] contended that a serious problem for Arab students is in the use of singular nouns where the plural should be used. Another way is to view the error as an omission of the plural marker. Reference [10] pointed out that in foreign language texts; one of the typical errors is pluralization of the descriptive nouns in the compounds.

On the other hand reference [7] found out that pronouns and pronominal reference do not seem to be problematic for Arab learners of English. Pronouns are usually introduced very early in school textbooks, they are very frequent, and there is not much room for interference from Arabic.

\section{2. $\quad$ Research Questions}

1. Which area of the NP is more problematic for students?

2. What types of NP errors are common in the discourse of high school students in Zawiya?

3. What are the potential sources of the errors students make in the use of the NP?

4. Is negative transfer from Arabic the major cause for errors?

The above questions deserve investigation since pointing out students' errors in NP constructions might help students overcome some of the difficulties they face.

\subsection{Purpose of the Study}

The aims of this research are to:

- Point out what area of the NP is the most problematic for students and try to suggest possible techniques to address this difficulty.

- Point out the sources of errors made by students and work on eliminating them.

- Come up with recommendations in order for teachers to help their students get rid of errors they make.

- Help students overcome a large number of errors they make regarding the NP.

\subsection{Participants}

\section{Research Methodology}

The subjects for the study were selected randomly from different high schools in Zawiya city. They were third year students as at this stage students should have fair knowledge of the different forms of the English NP. The sample included (100) students. There were (58) females and (42) males and their age ranged between (17) and (19). All were native speakers of Arabic and shared the same educational background.

It is hypothesized that the participants studied Modern Standard Arabic for fairly a long time. Arabic has two spoken forms of the language - colloquial and standard (diglossia). These two different forms of speech live side by side and are used in different contexts.

\subsection{Data Collection}

The questionnaire administered for the data collection has been adapted from reference [11]. The purpose was to test learners' knowledge of the different components of the NP. The questionnaire items test students in two main areas namely; errors in determiners and in nouns. Thirteen different possibilities of error concerning the noun head and the closed system elements that can occur before or after the noun head were checked. 
The table below includes a list of the secondary schools in Zawiya city where the study was carried out.

\begin{tabular}{|c|c|c|}
\hline No & School name & Number of students \\
\hline 1 & |assahl ala:xdar/ السهل الأخضر / & 13 \\
\hline 2 & | الأمل الأخضر /ala:mal ala:xdar/ الأر/ & 11 \\
\hline 3 & الزية / الز اوية الجنوبية /azzawya alzanu:byaa/ & 19 \\
\hline 4 & /alfa:tah/ الفاتح / & 18 \\
\hline 5 & 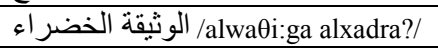 & 23 \\
\hline 6 & الوحدة للغات /alwihhda liluġa:t/ & 16 \\
\hline
\end{tabular}

Table 1: Schools where the study was carried out

\section{An Analysis and Discussion of the Learners' Difficulties in Using the English NP}

\subsection{Data Analysis}

Table 2 shows that the two main areas of the NP namely; the noun and the determiner are equally problematic for students. The subjects made a total of 2418 errors in the use of the NPs, which were divided into 943 committed in the area of determiners and 1475 committed in the area of nouns. There were 20 questions out of 50 concerning errors committed in determiners and 30 out of 50 concerning errors in nouns. The analysis of the two areas revealed that the percentage of learners' errors committed in the area of determiners was $49 \%$, while $51 \%$ of the total numbers of errors were committed in the area of nouns.

\begin{tabular}{|c|c|c|c|}
\hline Area of Errors & No of Questions & No of Errors & Percentage \\
\hline Determiners & 20 & 943 & 49.0 \\
\hline Nouns & 30 & 1475 & 51.0 \\
\hline Total & 50 & 2418 & $100 \%$ \\
\hline
\end{tabular}

Table 2: Errors committed in the areas of determiners and nouns

The Pie chart below illustrates the two main areas of difficulty of the NP for the students. Both areas accounted for approximately half the errors committed by the students.

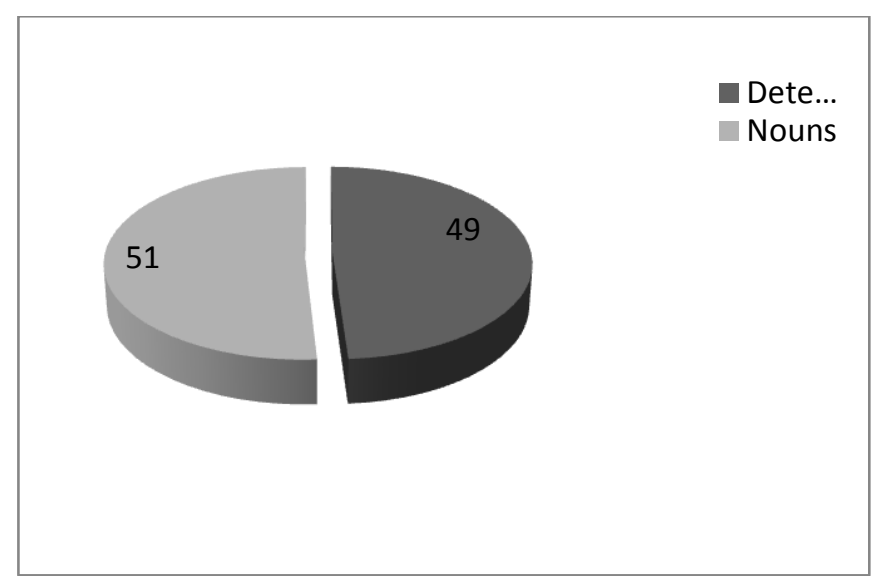

Pie Chart 1: Errors committed in the areas of determiners and nouns

In order to obtain a better overall view of each group of questions that deal with one type of error (e.g. definiteness, quantifiers etc), the number of questions for each type of errors, the number of responses, the number of correct and incorrect responses and Chi-square test were collected in the table below.

\begin{tabular}{|c|c|c|c|c|c|c|c|c|c|}
\hline \multirow[t]{2}{*}{ No } & \multirow[t]{2}{*}{ Type of errors } & \multirow[t]{2}{*}{$\begin{array}{l}\text { Number of } \\
\text { questions }\end{array}$} & \multirow[t]{2}{*}{$\begin{array}{l}\text { Number of } \\
\text { responses }\end{array}$} & \multicolumn{2}{|c|}{$\begin{array}{l}\text { Number of } \\
\text { correct answers }\end{array}$} & \multicolumn{2}{|c|}{$\begin{array}{c}\text { Number of } \\
\text { incorrect } \\
\text { answers }\end{array}$} & \multirow[t]{2}{*}{$\begin{array}{l}\text { Chi- } \\
\text { square } \\
\text { test }\end{array}$} & \multirow[t]{2}{*}{$\begin{array}{l}\text { Sign- } \\
\text { ficance }\end{array}$} \\
\hline & & & & Freq & $\%$ & Freq & $\%$ & & \\
\hline 1 & $\begin{array}{c}\text { Definiteness/Indefinitene } \\
\text { ss }\end{array}$ & 4 & 400 & 204 & 51.0 & 196 & 49.0 & 0.200 & .654 \\
\hline 2 & Quantifiers & 4 & 400 & 198 & 49.5 & 202 & 50.5 & 0.111 & .739 \\
\hline 3 & Demonstratives & 4 & 400 & 226 & 56.5 & 174 & 43.5 & *6.760 & .009 \\
\hline 4 & Word order & 3 & 300 & 168 & 56.0 & 132 & 44.0 & 2.880 & .089 \\
\hline 5 & Possessive adjective & 4 & 400 & 188 & 47.0 & 212 & 53.0 & 0.360 & .548 \\
\hline 6 & Pronouns & 4 & 400 & 238 & 59.5 & 162 & 40.5 & $* * 28.880$ & .000 \\
\hline 7 & Plurality & 4 & 400 & 275 & 68.7 & 125 & 31.3 & $* 41.813$ & .000 \\
\hline
\end{tabular}


Interlanguage Syntax of the Noun Phrase in English: An Error Analysis of Third Year High School

\begin{tabular}{|c|c|c|c|c|c|c|c|c|c|}
\hline 8 & Complex constructions & 4 & 400 & 152 & 38.0 & 248 & 62.0 & ${ }^{* *} 23.040$ & .000 \\
\hline 9 & Possessive (s') & 4 & 400 & 128 & 32.0 & 272 & 68.0 & ${ }^{* *} 25.920$ & .000 \\
\hline 10 & Numerals & 4 & 400 & 220 & 55.0 & 180 & 45.0 & 1.0 & .317 \\
\hline 11 & Noun Derivation & 3 & 300 & 126 & 42.0 & 174 & 58.0 & ${ }^{*} 5.120$ & .023 \\
\hline 12 & $\begin{array}{c}\text { Nouns and Other Related } \\
\text { Grammatical Forms }\end{array}$ & 4 & 400 & 218 & 54.5 & 182 & 45.5 & 1.620 & .203 \\
\hline 13 & $\begin{array}{c}\text { Countable vs. } \\
\text { Uncountable }\end{array}$ & 4 & 400 & 241 & 60.3 & 159 & 39.7 & $* * 12.813$ & .000 \\
\hline & Total & 50 & 5000 & 2582 & 51.6 & 2418 & 48.4 & & \\
\hline
\end{tabular}

Table 3: Thirteen different types of errors

1. Item (1), (Definiteness/Indefiniteness): Table 3 above shows that there were four questions concerning this type of error. It also shows that 204 responses out of 400 were correct while 196 were incorrect. In order to investigate the significant difference between the correct and incorrect answers Chi-square $\left(\chi^{2}\right)$ was used. The value of the $\left(\chi^{2}\right)$ was 0.200 which was not significant because its significance level was 0.456 which is higher than the 0.05 level of significance. The lower the significance level, the more the data diverge. Therefore there were no significant differences between the two frequencies concerning this type of error.

The findings presented in the table above indicated that more than half of the students under investigation were incapable of using the English articles effectively. This finding supports reference's [12] EA study on Arab students. Reference [12] concludes that definiteness problems were far more frequent than any other problem in English syntax faced by Arab students of English. According to reference [13] the use of the English article is a serious source of difficulty to Arabic-speaking students. It has also been proved that one of the main sources of difficulty in using those articles comes from interference from Arabic. Arabic uses a different system for indicating definiteness and indefiniteness in the language. English employs a tripartite system to express definiteness/indefiniteness, namely: a/an, the, and zero, whereas Arabic employs a binary system namely: (ل) and zero. Part of the confusion in using the English articles arises from this main difference between the two systems.

2. Item (2) was problematic for the students. The percentage of the correct answers was $49.5 \%$ and $50.5 \%$ of the students failed to answer this set of questions. The errors were related to the use of English quantifiers. The test results show that there were no big differences between the frequencies of the correct and incorrect answers. This was due to the value of $\left(\chi^{2}\right)$ which was 0.111 and its significance level was 0.736 which is higher than the 0.05 level of significance.

3. Item (3), (Demonstratives), can be regarded as less difficult than the other items for the students to master. Thus, $56.5 \%$ of the students got this set of questions correct, but 43.5 of them got it incorrect. The $\left(\chi^{2}\right)$ value of 6.760 shows that the differences between the two frequencies were quite significant. Also the $\left(\chi^{2}\right)^{\text {'s }}$ significance level of 0.009 which is less than the 0.05 level of significance indicates this difference.

4. Item (4) constituted a problem for students. $56.0 \%$ of them answered this item correctly and $44.0 \%$ failed to do so. The test results also show that there were 168 correct responses out of 300 while 132 were incorrect. The value of $\left(\chi^{2}\right)$ was 2.880 and its significance level was 0.089 which is higher than the 0.05 level of significance. Therefore there were no significant differences between the two frequencies concerning this type of error.

5. Item (5) shows that the number of correct answers was 188 out of 400 , so the percentage was $47.0 \%$. While the number of incorrect answers was 212 , thus the percentage was $53.0 \%$. The test results show that there were no significant differences between the frequencies of the correct and incorrect answers. This was due to the value of $\left(\chi^{2}\right)$ which was 0.360 and its significance level was 0.548 which is higher than the 0.05 level of significance.

6. Statistical calculations concerning item 6 (pronouns) show that there were four questions testing students in choosing the suitable pronoun. The data show that there were 238 correct responses out of 400 while 162 were incorrect. The $\left(\chi^{2}\right)$ value of 28.880 shows that the differences between the two frequencies were quite significant. Also the $\left(\chi^{2}\right)$ significance level of 0.000 which is less than the 0.01 level of significance indicates this difference.

7. Item (7) was the least difficult for the students. 275 out of 400 answers were correct, while 125 failed to make a correct choice according to this set of questions. The value of $\left(\chi^{2}\right)$ was 41.813 and its significance level was 0.000 which is less than the 0.01 level of significance. Both the value and the significance level of $\left(\chi^{2}\right)$ indicate that the frequencies were, to a great extent, different.

8. Item (8) constituted great difficulty for the students. Thus, only $38.0 \%$ of the students gave the correct answer, but $62.0 \%$ of them failed to answer it. Being 0.000 the $\left(\chi^{2}\right)$ significance level as well as its value of 23.040 indicate that the discrepancy between the correct and incorrect answers were highly significant. The errors of this item were committed due to the complexity of the construction in English. 
9. Item (9), (Possessive $\{$ ' $\mathrm{s} / \mathrm{s}$ ' $\}$ ), was the most problematic for the students. While only $32.0 \%$ of the students got it correct, $68.0 \%$ were not able to answer this set of questions correctly. The data also show that there were 128 correct responses out of 400 while 272 were incorrect. The $\left(\chi^{2}\right)$ value of 25.920 shows that the differences between the two frequencies were quite significant. Also the $\left(\chi^{2}\right)$ 's significance level of 0.000 which is less than the 0.05 level of significance indicates this difference.

10. Statistical calculations regarding errors made by the students in the use of English numerals show that there were 220 correct responses out of 400 while 180 were incorrect. The test results show that there were no big differences between the frequencies of the correct and incorrect answers. This was due to the value of $\left(\chi^{2}\right)$ which was 1 and its significance level was 0.317 which is higher than the 0.05 level of significance.

This finding supports the findings reached at by reference [14]. It concluded that the use of numerals and general ordinals seemed to be very problematic for Arab learners of English.

11. Noun Derivation: Statistical calculations concerning this type of error show that there were 126 correct responses out of 300 while 174 were incorrect. The value of $\left(\chi^{2}\right)$ was 5.120 and its significance level was 0.023 which is less than the 0.01 level of significance. Both the value and the significance level of $\left(\chi^{2}\right)$ indicate that the frequencies were, to some extent, different.

12. This item was less difficult for the students. The data show that there were 218 correct responses out of 400 , so the percentage was $54.5 \%$. While the number of incorrect answers was 182 , thus the percentage was $45.5 \%$. Being 0.203 the $\left(\chi^{2}\right)$ significance level as well as its value of 1.620 indicate that the discrepancy between the correct and incorrect answers were not very significant. Errors committed here were due to the confusion of nouns with other related grammatical forms.

13. Countable vs. Uncountable nouns were less problematic for the students. The data show that there were 241 correct responses out of 400 while 159 were incorrect. So, 60.3 of them gave the correct answers, whereas 39.7 gave wrong ones. The $\left(\chi^{2}\right)$ 's value was 12.813 and its significance level was 0.000 . This shows that there were significant differences between the two frequencies concerning this type of error.

The distinction between count and noncount nouns in English and Arabic is language specific, with the result that items belonging to one category (e.g. noncount) in one language are not necessarily the same in the other language. For instance, the nouns leisure and homework are noncount in English, but there Arabic counterparts are count nouns. Therefore, the student will probably form plurals from such words.

The Bar chart 1 below shows the percentage of the thirteen different types of errors drawn in bars. The bars on the left represent the correct answers and the bars on the right represent the incorrect ones. One can notice that the most significant difference between the correct and incorrect answers were mainly in the use of plurality, possessive ('s), complex constructions, countable vs. uncountable nouns and pronouns.

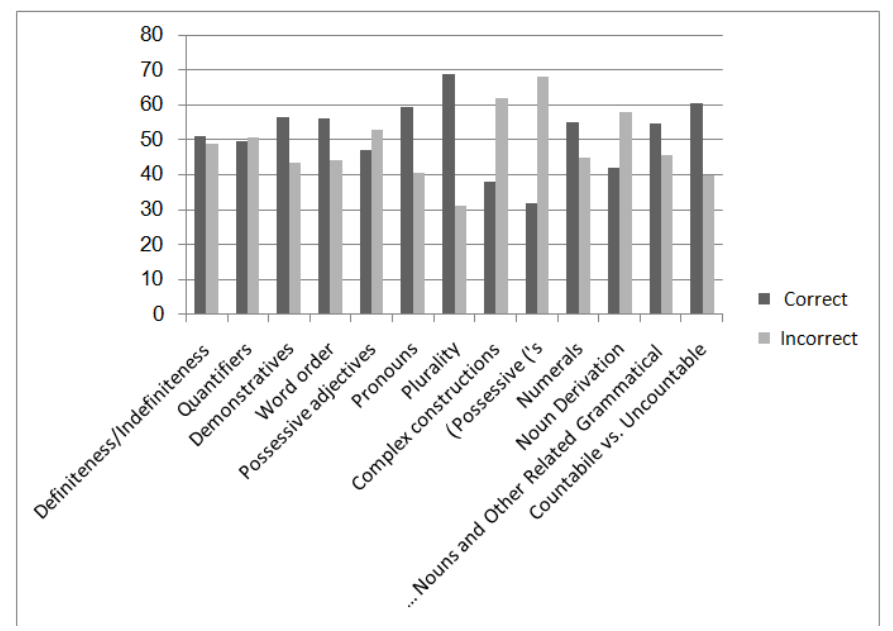

Bar Chart 1: Thirteen different types of errors

\subsection{Explanation of Students' Errors}

Errors collected from the test can be attributed to more than one source, the most obvious of which may be L1 transfer, for the learners may be giving the equivalent L1 structure as the result of their inadequate knowledge of that of the L2, as shown in the examples below:

* 1 . Is a bee insect?

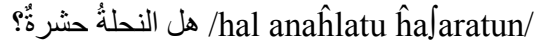

* 2. What's your number phone?

ما رقمُ هاتفكَكْ/ma raqmu hatifika/

* 3. Mike wants to watch TV the tonight. 
مايك يريدُ أن يشاهدَ التلفزيونَ الليلة.

* 4. He came the first in the race.

لق أحرزَ المركز الاول في السباق. /laqad aĥraza almarkaz alawal fi assibaq/

* 5. The sea is dirty. There is oil on him.

البحرُ متسخُ. يوجدُ زيتُ عليهِ.

* 6. How many student are there in your class?

كم طالبُّ في فصلكَ؟ kam ţalibun fi fašlika/

* 7. That's my car new!

تارئل سيارني الجديدة.

In example (1), a considerable number of the subjects made the error of deleting the indefinite article an whose use was obligatory with the singular countable noun insect. While English requires the use of an indefinite article, Arabic shows indefiniteness by not using an article at all. Due to these differences between the two languages, ungrammatical structures were produced. The fact that Arabic does not have a distinct marker for indefiniteness the way English does is probably the cause of the learners' deviation from the L2 rule.

In (2), an error in word order occurs. The adjective in Arabic comes after the noun it modifies whereas in English the adjective precedes the noun. As a result, some students applied the same Arabic order to English. This shows that this type of error is a negative transfer.

In (3) and (4), many students produced definite nouns the tonight and the first where the zero article should be used.

In (5), students chose the object pronoun him as Arabic does not have an inanimate third person pronoun. Student's choice was based upon gender only because oil in Arabic is masculine.

Arabic suggests a singular noun after the quantity question mark $1 /$ whereas English suggests a plural or uncountable noun. This was probably the reason which made students chose the singular noun student in (6).

Analogy or overgeneralization of other L2 structures could be offered to explain the following set of errors. The learners were probably applying English language rules where they were not applicable, as shown in the examples below:

* 8. She works as clerk in a very big bank.

* 9. How many butter do you need?

* 10. This students are looking for their ball.

* 11 . He is a flight attender.

* 12. I bought some fishes.

* 13. Terry is talking to two womans.

* 14. My tooths hurt.

* 15. He is a good cooker.

* 16. I put a little banana on the cake. I don't like it very much.

Another potential source for the error in (8) could be the strategy of simplification. Learners could be attempting to reduce the learning burden whereby the L2 structure was simplified into a form which was compatible with the learners' still developing IL system. They might be using the zero article with both singular and plural unidentified countable nouns which would certainly reduce the system into a more manageable one.

In other cases there was no transfer or overgeneralization but probably confusion in the use of the correct word. Such errors could be due to the fact that some English language structures are inherently difficult. The following were some examples:

* 17. Look at that house. All it's windows are broken. (its windows)

* 18. A: Whose house is that? B: It's the Taylor. (Taylor's)

* 19. A: Is Allie's new dress blue? B: No, her is green. Helen's is blue. (hers)

* 20. The policeman is holding the robber right arm. (robber's)

* 21. You can find the medicine at the chemist. (chemist's)

* 22. The boys are holding up there hands. (their)

* 23. A: May I help you? B: Yes, I want three cans beans. (cans of beans)

* 24. We can all get on the bus. There are only many passengers on it now. (a few)

* 25. The postman gave me three of letters, so I gave them to my mother. (three letters)

Other errors could not be traced back to any source. These errors might be due to the teaching methods and techniques used in teaching. The focus of teaching method could be on structural words within sentences not on complete patterns of language. Therefore, the students learn the meaning of the words but they cannot use them properly. Here are some examples:

* 26. Can you see those boys and them father? (their)

* 27. John and I washed we hands. (our)

* 28. What's the different between them? (difference)

* 29. I don't have some petrol in my car. (any) 
* 30. Emily is a nineteen years-old student. (year-old)

* 31. I've been awarded $\boldsymbol{a}$ two-years scholarship. (a two year)

Other errors were probably the result of the faulty presentation of a word or a structure in the textbook, a pattern that was rotely memorized but not properly contextualized or a misleading explanation from a textbook writer or the teacher who may provide inaccurate or incomplete knowledge.

\subsection{Hierarchy of Difficulty}

The following table presents the hierarchy of difficulty for using and forming NPs in English. One can notice that types of errors have different degrees of difficulty. The difficulty of using the NP moved down from the most difficult type which was genitives to the less difficult which was plurality.

The construction of hierarchy of difficulty depends on the assumption that some correspondents are more difficult to master than others (including, as correspondences, those instances where a rule in one language finds no corresponding rule in the other, or where a category in one is unmatched by a category in the other). The hierarchy is a set of predictions which must be tested against observation of the problems students do in fact have [15].

\begin{tabular}{|c|l|c|}
\hline No & Type of Errors & $\begin{array}{c}\text { Percentage of } \\
\text { Difficulty }\end{array}$ \\
\hline 1 & Possessive (s') & $\% 68.0$ \\
\hline 2 & Complex Constructions & $\% 62.0$ \\
\hline 3 & Noun Derivation & $\% 58.0$ \\
\hline 4 & Possessive adjective & $\% 53.0$ \\
\hline 5 & Quantifiers & $\% 50.5$ \\
\hline 6 & Definiteness/Indefiniteness & $\% 49.0$ \\
\hline 7 & Nouns and Other Related Grammatical Forms & $\% 45.5$ \\
\hline 8 & Numerals & $\% 45.0$ \\
\hline 9 & Word Order & $\% 44.0$ \\
\hline 10 & Demonstratives & $\% 43.5$ \\
\hline 11 & Pronouns & $\% 40.5$ \\
\hline 12 & Countable vs. Uncountable & $\% 39.7$ \\
\hline 13 & Plurality & $\% 31.3$ \\
\hline
\end{tabular}

Table 4: shows the thirteen types of errors arranged from the most to the least difficult

\subsection{Summary of the Results}

This study is set out to investigate kinds of errors made by the $3^{\text {rd }}$ year secondary school students in the use of the English NP. The research findings reveal that students at this level experience serious difficulties in using the correct NP. The findings also reveal that both the area of nouns and the area of determiners are equally difficult. The analysis shows that the most difficult type of errors were possessives, complex constructions, noun derivation, possessive adjectives, quantifiers, definiteness and indefiniteness, confusion of nouns with other parts of speech, numerals, word order, demonstratives, pronouns, countability and plurality respectively.

Mother tongue interference is a learning strategy that most EFL learners fall back on especially in classroom situations where exposure to the TL is confined to a few hours per week of formal instruction. Interference was surely the most noticeable source of error among students concerning the use of the NP. It is also clear from learning theories that a learner will use whatever previous experience she/he has had with language in order to facilitate the L2 learning process.

The students' errors are not a result of their L1 alone, but are rather due to several factors among of which are overgeneralization, teaching methods, teaching materials and also because some English constructions are inherently difficult.

\subsection{Conclusion}

\section{Concluding Remarks and Recommendations}

On the basis of the results obtained from this study, one can conclude that some Libyan third year secondary school students encounter difficulties in using NPs in English. Libyan learners of English had problems with definiteness in English mainly because of the difference in the expression of reference in English and Arabic. Quantifiers were confused as to their use with count/non-count nouns. Other errors included the misformation of nouns, possessive $\left(\mathrm{s}^{6}\right)$, and the confusion of nouns with other related grammatical forms. While a great number of these errors can be explained by overgeneralization and interference between English and 
Arabic, some other errors challenge explanations offered by the Contrastive Analysis. The impact of the subjects' L1 was found the most noticeable source of error.

\subsection{Recommendations}

In the light of the findings of this study, the following recommendations can be made:

- In order to avoid overgeneralization errors, teachers should teach not only the mechanics of grammatical rules, but also to teach them the correct distribution and exceptional cases where they do not apply.

- Teachers should use suitable periodical evaluation tests to diagnose areas of weakness in learners' use of NPs and to know to what extent lessons have been understood. If an already explained lesson or part of it is not understood, another explanation should take place with a different method.

- When Arabic interference seems to be the source of error, it can be explained briefly to students.

- It would be very useful to increase the number of exercises and homework for the sake of which the students would have to do a lot of work during their free time, hence they would be reading a lot of English material and thinking in English, especially if they have to make oral tasks for their work. In addition, if we implement team work in class and we get the students to work in groups on their work and exercises, they would have to practice together for their oral tasks, and speak English with each other instead of Arabic. Besides, they would, hopefully, correct each other's mistakes.

- Rather than leave the students to make their own comparisons and associations with their L1, perhaps teachers could encourage referring back to L1 when the items to be taught are similar in the two languages. They could elicit comparisons that would help the students learn about the English language.

\section{References}

[1]. Chomsky, N. (1959). A Review of B. F. Skinner Verbal Behaviour. Language 35 (1): 26-58.

[2]. Spolsky, B. (1989). Conditions for Second Language Learning. Oxford: Oxford University Press.

[3]. Ellis, R. (1994). The Study of Second Language Acquisition. Oxford: Oxford University Press.

[4]. Richards, J. C. (1974). Error Analysis: Perspectives on Second Language Acquisition. Essex: Longman.

[5]. Langacker, W., R. (1972). Fundamentals of Linguistic Analysis. New York: Harcourt Brace Jovanovich Inc.

[6]. Brown, R. (1973). A First Language. Massachusetts: Harvard University Press.

[7]. Zoghoul, M. (2002). Interlanguage Syntax of Arabic-Speaking Learners of English. Master thesis, Yarmouk University, Jordan. Retrieved March 25, 2009, from Education Resources Information Center database.

[8]. Arabski, J. (1979). Errors as Indicators of the Development of Interlanguage. Katowice: Universytet Slaski.

[9]. Celce-Murcia, M. \& Larsen-Freeman, D. (1983). The Grammar Book: An ESL/EFL Teacher's Course. Massachusetts: Newbury House Publishers.

[10]. Hinkel, E. (2004). Teaching Academic ESL Writing: Practical Techniques in Vocabulary and Grammar. New Jersey: Lawrence Erlbaum Associates.

[11]. Quirk, R. \& Greenbaum, S. (1990). A Student's Grammar of the English Language. London: Longman.

[12]. Willcott, P. (1972). An Analysis of the Written English of Native Speakers of Arabic as Found in American History Final Examinations at the University of Texas at Austin. Doctoral dissertation, The University of Texas at Austin. Retrieved March 25, 2009, from Education Resources Information Center database.

[13]. Kharma, N. (1981). Analysis of the Errors Committed by Arab University Students in the Use of English Definite/Indefinite Articles. International Rivew of Applied Linguistics, 19, 331-345.

[14]. Quirk, R. \& Greenbaum, S. (1977). A University Grammar of English. London: Longman.

[15]. Stockwell, R., Dowen, D \& Martin, J. (1965). The Grammatical Structures of English and Spanish. Chicago: Chicago University Press. 